\title{
USO DO IRRIGÂMETRO PARA ESTIMAR A EVAPOTRANSPIRAÇÃO DE REFERÊNCIA COM BASE NO MÉTODO DO LISÍMETRO DE LENÇOL FREÁTICO CONSTANTE
}

\author{
Cristiano Tagliaferre ${ }^{1}$, Rubens Alves de Oliveira ${ }^{2}$, Gilberto Chohaku Sediyama ${ }^{2}$, Paulo Roberto Cecon ${ }^{3}$, Franklin \\ José Valbuena Materán ${ }^{4}$
}

\begin{abstract}
RESUMO
Os objetivos deste trabalho foram avaliar o Irrigâmetro para estimar a evapotranspiração de referência $\left(\mathrm{ET}_{0}\right)$ e comparar os métodos de FAO-Penman-Monteith, FAO-Penman Modificado, FAO-Radiação, Hargreaves-Samani e Tanque Classe A, em relação ao método do lisímetro de lençol freático constante. Os dados de evapotranspiração de referência $\left(\mathrm{ET}_{0}\right)$, obtidos com o Irrigâmetro e com os demais métodos, foram comparados com os valores medidos no lisímetro de lençol freático constante, operando com Irrigâmetro modificado, em intervalos de um, três, cinco e sete dias. Os resultados mostraram que o Irrigâmetro apresentou desempenho satisfatório para estimar a $\mathrm{ET}_{0}$, em todos os intervalos de tempo estudados, com comportamento semelhante ao das estimativas proporcionadas pelo método de FAO-Penman Modificado. Assim, o Irrigâmetro pode ser utilizado para o manejo da água na agricultura irrigada, com as vantagens adicionais de custo relativamente baixo, alta praticidade e não envolver cálculos. Os demais métodos estudados superestimaram os valores da $\mathrm{ET}_{0}$, obtidos pelo método do lisímetro de lençol freático constante, tendo o Tanque Classe A apresentado comportamento contrário.
\end{abstract}

Palavras-chave: evaporímetro, manejo da irrigação, agricultura irrigada.

\section{USE OF IRRIGAMETER TO ESTIMATE REFERENCE EVAPOTRANSPIRATION RATE BASED ON THE CONSTANT WATER TABLE LYSIMETER METHOD}

\begin{abstract}
This work was carried out to evaluate the performance of an irrigameter to estimate the reference evapotranspiration rate $\left(\mathrm{ET}_{0}\right)$ and compare it with the methods of FAO-Penman-Monteith, FAO-Modified Penman, FAO-Radiation, Hargreaves-Samani and Class A pan evaporation rate, relative to the constant water table lysimeter method. The ET 0 data obtained after one, three, five and seven days, with the use of the irrigometer were compared with the measured values of the constant water table lysimeter, operating with the modified irrigometer. The irrigameter results were satisfactory to estimate $\mathrm{ET}_{0}$ in all time intervals studied, and similar to the method of Modified Penman - FAO 24. It was concluded that the irrigameter is reliable and can be used for irrigation water management, with the advantages of relatively low cost, highly practical and without involving complex calculations. The others methods overestimated $\mathrm{ET}_{0}$ compared to the method of constant water table lysimeter, and the Class A pan showed opposite behavior.
\end{abstract}

Keywords: evaporimeter, irrigation management, irrigated agriculture.

\footnotetext{
Recebido para publicação em 11/03/2010. Aprovado em 09/06/2010

1- Professor do Departamento de Engenharia Agrícola da universidade Estadual Sudoeste da Bahia, Vitória da Conquista, BA, tagliaferre@uesb.br,

2- Professores do Departamento de Engenharia Agrícola da Universidade Federal de Viçosa, Viçosa, MG, rubens@ufv.br; g.sediyama@ufv.br

3- Professor do Departamento de Informática da Universidade Federal de Viçosa, Viçosa, MG, cecon@dpi.ufv.br

4- Professor da Universidad del Zulia, Venezuela, franklinvalb@yahoo.com
}

152 REVENG

152-163 p. ENGENHARIA NA AGRICULTURA, VIÇOSA - MG, V.19 N.2, MARÇO / ABRIL 2011 


\section{INTRODUÇ̃̃O}

Existem diferentes métodos de estimativa da evapotranspiração de referência. De acordo com Burman et al. (1983), a evapotranspiração de referência pode ser obtida a partir de medidas diretas, ou estimada a partir de elementos climáticos, utilizando-se modelos ou métodos teóricos empíricos. As medidas diretas são obtidas por meio de lisímetros, que, segundo Howell et al. (1991), podem ser agrupados em três categorias: (a) não pesáveis com lençol freático de nível constante; (b) não pesáveis com drenagem livre; (c) lisímetros pesáveis, em que a variação de massa do sistema é determinada por um mecanismo de pesagem. Nos lisímetros não pesáveis com lençol freático de nível constante, o nível da água é mantido em determinada profundidade. Já os métodos teóricos ou métodos micrometeorológicos, que são baseados em princípios físicos, apresentam alta precisão, mas têm limitações por necessitarem de instrumentação adequada, impedindo a sua utilização, na maioria das vezes (BERLATO \& MOLION, 1981). Entretanto, os métodos empíricos são muito utilizados na estimativa da evapotranspiração de referência, em virtude de sua praticidade de aplicação, facilidade de obtenção dos elementos climáticos e por facilitar o uso da programação computacional, dos quais se destacam os modelos de FAO-PenmanMonteith, FAO-Penman Modificado, FAORadiação, Hargreaves-Samani (1985) e Tanque Classe A.

No uso do Tanque Classe A para manejo da irrigação, a medição da lâmina de água evaporada e a sua conversão em evapotranspiração exigem que o irrigante faça anotações e cálculos para definir o momento de irrigar, a lâmina a ser aplicada e o tempo de irrigação.

Atualmente, o uso de estação meteorológica automática tem facilitado o emprego dos métodos que utilizam variáveis climáticas; no entanto, o seu uso tem sido limitado a grandes áreas irrigadas. Tal fato ocorre, principalmente, em função do seu custo elevado, por envolver a aquisição de computador, programa computacional, manutenção periódica, assistência técnica especializada, além de certo conhecimento técnico do irrigante sobre irrigação. Ley et al. (1994a e 1994b) mencionam que, quando a medição dos elementos meteorológicos é feita por estações meteorológicas automáticas, é comum a ocorrência de erros decorrentes da calibração dos sensores dos equipamentos, utilizados para essas medições, comprometendo, dessa forma, a determinação dos elementos climáticos necessários à estimativa da evapotranspiração.

O Irrigâmetro é um aparelho evapopluviométrico, empregado no manejo da irrigação, visando a aperfeiçoar o uso da água na agricultura irrigada. Ele foi desenvolvido e patenteado, no ano de 2005, na Universidade Federal de Viçosa. O Irrigâmetro simplifica o manejo da água em áreas irrigadas, pois fornece resposta prática às três questões básicas do manejo de irrigação: a) quando irrigar; b) quanto irrigar; c) por quanto tempo o equipamento de irrigação deve funcionar.

Oliveira et al. (2008) avaliaram o Irrigâmetro para estimar diretamente a evapotranspiração de referência $\left(\mathrm{ET}_{0}\right)$, comparando o seu desempenho com estimativas obtidas, utilizando-se os métodos de FAO-Penman Modificado, FAORadiação, Hargreaves_Samani e Tanque Classe A, tendo como padrão o método de FAO-PenmanMonteith. Neste estudo, foi verificado que o Irrigâmetro apresentou bom desempenho na estimativa da $\mathrm{ET}_{0}$ em períodos de um, três, cinco e sete dias, o que levou o autor a recomendar o seu uso no manejo da irrigação.

Em estudos envolvendo a aplicabilidade da tecnologia do Irrigâmetro em lisímetros com lençol freático constante, Materan (2006) encontrou bom ajuste dos valores diários de $\mathrm{ET}_{0}$, obtidos com os lisímetros, com os estimados utilizando-se o método de FAO-PenmanMonteith. Os bons resultados encontrados foram resultantes da alta sensibilidade de leitura da lâmina evapotranspirada, igual a $0,018 \mathrm{~mm}$. De maneira semelhante, Tagliaferre et al. (2006) avaliaram o minievaporímetro UFV-1, operando com Irrigâmetro modificado para estimativa da $\mathrm{ET}_{0}$, com níveis de água dentro do evaporatório mantidos a 30, 45, 60 e $75 \mathrm{~mm}$ da borda. O minievaporímetro 
apresentou excelente desempenho para estimar a $\mathrm{ET}_{0}$, em períodos de um, cinco e sete dias, para todos os níveis estudados, destacando-se frente às estimativas efetuadas utilizando-se os métodos de FAO-Pemnan Modificado, Radiação, HargreavesSamani e Tanque Classe A, tendo como padrão o método FAO-Penman-Monteith.

Avaliar a utilização do Irrigâmetro para estimativa de evapotranspiração de referência $\left(\mathrm{ET}_{0}\right)$ e comparar os resultados obtidos utilizando-se os métodos de FAO-Penman-Monteith, FAO-Penman Modificado, FAO-Radiação, Hargreaves-Samani (1985) e Tanque Classe A, em relação ao método do lisímetro de lençol freático constante, foram os objetivos deste trabalho.

\section{MATERIAL E MÉTODOS}

O estudo foi conduzido na Universidade Federal de Viçosa, em Viçosa, MG, situada a $20^{\circ} 45^{\prime} 14^{\prime \prime}$ $\mathrm{S}$ e $42^{\circ} 52^{\prime} 55^{\prime \prime} \mathrm{O}$, numa altitude média de $651 \mathrm{~m}$. Os elementos climáticos diários foram obtidos numa estação climatológica do INMET (Instituto Nacional de Meteorologia), localizada no Campus da UFV, próximo à área experimental.

A estimativa da $\mathrm{ET}_{0}$ foi realizada utilizando-se um Irrigâmetro, o método FAO-Penman-Monteith, FAO-Penman Modificado, FAO-Radiação, Hargreaves-Samani (1985), Tanque Classe A e o lisímetro de lençol freático constante, operando com um Irrigâmetro modificado, adotado como método padrão. No uso dos métodos FAO-PenmanMonteith, FAO-Penman Modificado, FAORadiação e Hargreaves-Samani, os valores de $\mathrm{ET}_{0}$ foram obtidos durante 47 dias, tendo sido calculados com o aplicativo computacional REF-ET (ALLEN, 2000).

No caso do Tanque Classe A, o seu coeficiente foi obtido diariamente por meio da aplicação da equação proposta por Allen \& Pruitt (1991), para tanques circundados por grama, com bordadura de grama igual a $5 \mathrm{~m}$. Nos períodos de três, cinco e sete dias, os valores de $\mathrm{ET}_{0}$ e do coeficiente do Tanque Classe A foram calculados, usando-se os valores médios dos elementos do clima. Para o lisímetro de lençol freático constante, usaram-se valores médios de $\mathrm{ET}_{0}$ no período de tempo analisado.

A evapotranspiração de referência foi medida no Irrigâmetro com precisão igual a $0,1 \mathrm{~mm}$. $\mathrm{Na}$ Figura 1 mostra-se o Irrigâmetro instalado na área experimental, com a escala da lâmina evapotranspirada e com as réguas que fornecem diretamente o tempo de irrigação, para certo sistema de aspersão convencional, e o momento de irrigar, para determinado tipo de cultura e de solo. No detalhe, tem-se a indicação da lâmina evapotranspirada $(11,5 \mathrm{~mm})$, do tempo de irrigação ( $1 \mathrm{~h} 40)$ e do momento de irrigar (faixa amarela). A tecnologia do Irrigâmetro está descrita em Oliveira \& Tagliaferre (2006).

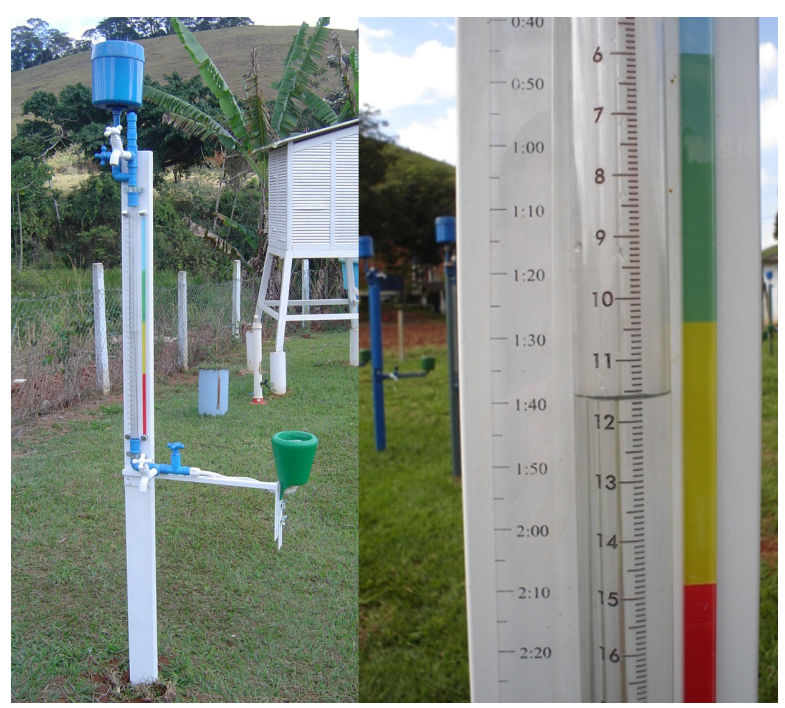

Figura 1. IrrigâmetroinstaladonaÁreaExperimental de Hidráulica, Irrigação e Drenagem do Departamento de Engenharia Agrícola da UFV, em Viçosa, MG.

Na Unidade de Pesquisa e Desenvolvimento do Irrigâmetro, foram utilizados três lisímetros cultivados com grama-batatais (Paspalum notatum L.), com lençol freático constante, mantido a $15 \mathrm{~cm}$ de profundidade. Os lisímetros foram construídos com caixa de cimento-amianto de 1000 L $(1,10$ $\mathrm{m}$ de largura, 1,60 $\mathrm{m}$ de comprimento e $0,70 \mathrm{~m}$ de profundidade), preenchidos com substrato de areia, com grânulos de tamanho menor que 1,0 $\mathrm{mm}$ e maior que $0,104 \mathrm{~mm}$, alimentados com solução nutritiva.

$\mathrm{Na}$ Figura 2 está ilustrado o lisímetro de lençol freático constante, operando com Irrigâmetro modificado, usado para estimativa da evapotranspiração de referência.

\section{REVENG 152-163 p.}




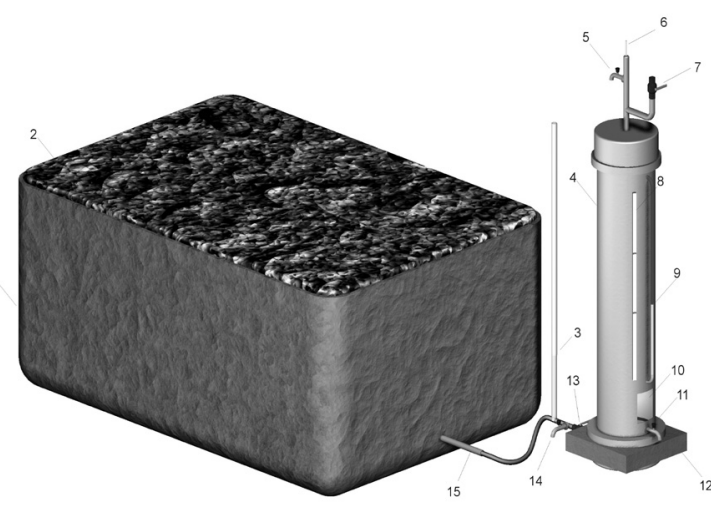

1. Caixa de cimento-amianto; 2. Grama-batatais; 3. Tubo piezométrico; 4. Tubo de leitura-alimentação; 5. Válvula de eliminação de ar; 6. Tubo de borbulhamento; 7. Válvula de abastecimento; 8. Escala de leitura; 9. Piezômetro; 10. Visor; 11. Válvula de drenagem; 12. Suporte; 13. Válvula interconectora; 14. Válvula pluvial; e 15. Tubo interconector.

Figura 2. Lisímetro de lençol freático constante, operando com Irrigâmetro modificado para estimativa da evapotranspiração de referência.

O fundo de cada lisímetro foi conectado ao Irrigâmetro modificado, por meio de um tubo de PVC com $20 \mathrm{~mm}$ de diâmetro. O Irrigâmetro modificado foi construído com tubo de leituraalimentação, de diâmetro interno de $195 \mathrm{~mm}$ e altura de $1.100 \mathrm{~mm}$, com escala graduada em milímetros. A relação entre as áreas internas do lisímetro e do tubo de leitura-alimentação do Irrigâmetro modificado, igual a 56,49, possibilitou uma sensibilidade na leitura da lâmina evaporada igual a $0,018 \mathrm{~mm}$. A evapotranspiração foi obtida pela diferença entre duas leituras consecutivas, num período de 24 horas, por um período de 42 dias.

$\mathrm{Na}$ extremidade inferior do tubo de leituraalimentação, existe uma válvula de drenagem, usada para retirar a água do tubo de borbulhamento e o excesso do tubo de leitura-alimentação, a fim de zerar o aparelho. Na parte superior, existem as válvulas de escapamento e a de abastecimento.

Durante o reabastecimento do tubo de leituraalimentação, a válvula interconectora deve estar fechada e as de escapamento e de abastecimento abertas. Após o reabastecimento, as duas últimas válvulas são fechadas, abrindo-se a válvula de drenagem, até zerar o aparelho. Em seguida, é restabelecido o seu funcionamento normal, por meio da abertura da válvula interconectora.

Ao final de cada dia e nos dias chuvosos, cada lisímetro era coberto com telha de fibra de vidro transparente, de $1 \mathrm{~mm}$ de espessura, fixada em um suporte de madeira com altura de $60 \mathrm{~cm}$, o qual era removido no início de cada dia. Assim, a precipitação pluvial foi eliminada da contabilização da lâmina evapotranspirada. A determinação da $\mathrm{ET}_{0}$ no lisímetro de lençol freático constante foi feita por meio da diferença entre duas leituras sucessivas no irrigâmetro modificado.

A análise do desempenho do Irrigâmetro foi feita, comparando-se os valores de evapotranspiração de referência, obtidos no aparelho, com os medidos pelo método do lisímetro de lençol freático constante. A metodologia adotada para comparação dos resultados foi proposta por Allen (1986) e adotada por Jensen et al. (1990), a qual se fundamenta na Estimativa do Erro Padrão (EEP).

A hierarquização das estimativas da evapotranspiração foi feita, baseando-se nos valores de estimativa do Erro Padrão, do Coeficiente de Determinação $\left(r^{2}\right)$ e do Coeficiente Angular (b) das respectivas regressões lineares simples. A melhor alternativa foi aquela que apresentou maior $\mathrm{r}^{2}$, menor EEP e b próximo da unidade.

A precisão foi dada pelo Coeficiente de Determinação, a qual indica o grau em que a regressão explica a soma do quadrado total. A aproximação dos valores de $\mathrm{ET}_{0}$ estimados por determinado método estudado, em relação aos valores obtidos com uso do método padrão (lisímetro), foi obtida por um índice, designado de concordância ou ajuste, representado pela letra "d"(WILLMOTT et al., 1985). Seus valores variam desde zero, quando não existe concordância, a 1, para a concordância perfeita.

O índice de aproximação é calculado, aplicandose a seguinte expressão:

$\mathrm{d}=1-\frac{\sum_{\mathrm{i}=1}^{\mathrm{n}}(\mathrm{Pi}-\mathrm{Oi})^{2}}{\sum_{\mathrm{i}=1}^{\mathrm{n}}[(|\mathrm{Pi}-\overline{\mathrm{O}}|)+(|\mathrm{Oi}-\overline{\mathrm{O}}|)]^{2}}$

em que,

d - índice de concordância ou ajuste, adimensional;

$\mathrm{Pi}$ - evapotranspiração de referência obtida pelo método considerado, $\mathrm{mm} \mathrm{d}^{-1}$;

Oi - evapotranspiração de referência obtida pelo método padrão, $\mathrm{mm} \mathrm{d}^{-1}$; 
$\overline{\mathrm{O}}$ - média dos valores de ETo obtido pelo método padrão, $\mathrm{mm} \mathrm{d}^{-1}$; e

$\mathrm{n}$ - número de observações.

\section{RESULTADOS E DISCUSSÃO}

No Quadro 1 encontram-se apresentados os parâmetros da regressão $(a, b)$, o coeficiente de determinação $\left(r^{2}\right)$, a estimativa do Erro Padrão (EEP) e o índice de concordância (d), obtidos entre os valores de $\mathrm{ET}_{0}$ estimada no Irrigâmetro e pelos demais métodos estudados, com os valores medidos no lisímetro de lençol freático constante para períodos diários.

De acordo com os resultados, o método de FAO-Penman-Monteith para estimativa da evapotranspiração de referência, apresentou resultados satisfatórios para estimar a $\mathrm{ET}_{0}$ em períodos diários, com Erro Padrão da Estimativa de $0,51 \mathrm{~mm} \mathrm{~d}^{-1}$. Esse método superestimou a $\mathrm{ET}_{0}$ obtida no lisímetro de lençol freático constante em 9,83\%. Diversos trabalhos evidenciam o bom desempenho do método de FAO-Penman-Monteith, em relação aos lisímetros; dentre eles, podem-se citar Allen (1986), Camargo \& Sentelhas (1997), Sentelhas (1998) e Pereira (1998). O bom funcionamento do lisímetro e a sua precisão na medição da evapotranspiração de referência deveramse ao uso do Irrigâmetro modificado, o qual possibilitou maior sensibilidade de leitura.

Com relação ao método de Hargreaves-Samani e da FAO-Radiação, os EEP foram de 1,14 e 0,92 mm $\mathrm{d}^{-1}$, respectivamente. Esses métodos superestimaram a evapotranspiração de referência. De acordo com Jensen et al. (1990), os métodos que se baseiam na temperatura do ar e na radiação, como é o caso de HargreavesSamani, tendem a superestimar a evapotranspiração de referência em 15 a 25 \%, em climas úmidos. Quanto ao método da Radiação, observa-se que ele apresentou superestimativa da $\mathrm{ET}_{0}$ obtida no lisímetro. Lunardi et al. (1999) verificaram superestimativa da $\mathrm{ET}_{0}$ com uso do método da Radiação em Botucatu, Estado de São Paulo. Isso indica que este método necessita de calibrações locais para estimativa confiável da $\mathrm{ET}_{0}$.

$\mathrm{O}$ método de FAO-Penman Modificado, que leva em consideração os aspectos aerodinâmicos e de radiação, e o Irrigâmetro superestimaram os valores de evapotranspiração de referência, obtidos pelo método do lisímetro de lençol freático constante, com Erros Padrão das Estimativas iguais a 0,76 e $0,74 \mathrm{~mm} \mathrm{~d}^{-1}$. A análise conjunta dos valores do Coeficiente Angular, de Determinação e de Concordância, e do Erro Padrão da Estimativa indica que o Irrigâmetro teve desempenho igual ao do método de FAO-Penman Modificado, recomendado por Doorenbos \& Pruitt (1977). Sendo assim, o Irrigâmetro proporcionou a obternção de resultados confiáveis de estimativa da $\mathrm{ET}_{0}$ para períodos diários, que, associados ao baixo custo, à alta praticidade e à dispensa de cálculos adicionais, podendo ser indicado para utilização no manejo da água de irrigação.

O Tanque Classe A apresentou bom ajuste para períodos diários, com Erro Padrão da Estimativa igual a $0,45 \mathrm{~mm} \mathrm{~d}^{-1}$, apesar de ser recomendado, de maneira generalizada, para períodos de tempo superiores a dez dias para estimativa da $\mathrm{ET}_{0}$. Dentre os métodos estudados, o Tanque Classe A apresentou melhor estimativa da $\mathrm{ET}_{0}$.

Quadro 1. Parâmetros da Regressão $(a, b)$, Coeficiente de Determinação $\left(r^{2}\right)$, Erro Padrão da Estimativa (EEP) e o Coeficiente de Ajustamento (d), obtidos entre os valores de ET estimada no Irrigâmetro e pelos demais métodos estudados, com os valores medidos no lisímetro de lençol freático constante, para períodos diários

\begin{tabular}{lcccccc}
\hline Método & $\mathrm{A}$ & $\mathrm{b}$ & $\mathrm{r}^{2}$ & $\mathrm{EPE}$ & $\mathrm{d}$ & $\mathrm{ET}_{0}\left(\mathrm{~mm} \mathrm{~d}^{1}\right)$ \\
\hline Lisímetro de lençol freático constante & - & - & - & - & - & 2,95 \\
FAO-Penman-Monteith & 0,729 & 0,852 & 0,85 & 0,51 & 0,87 & 3,24 \\
FAO-Penman Modificado & 0,000 & 1,168 & 0,98 & 0,76 & 0,90 & 3,45 \\
Hargreaves-Samani & 2,081 & 0,749 & 0,72 & 1,47 & 0,69 & 4,29 \\
FAO-Radiação & 0,000 & 1,221 & 0,98 & 0,92 & 0,87 & 3,60 \\
Tanque Classe A & 0,589 & 0,772 & 0,84 & 0,45 & 0,95 & 2,86 \\
Irrigâmetro & 0,827 & 0,888 & 0,76 & 0,74 & 0,89 & 3,44 \\
\hline
\end{tabular}


$\mathrm{Na}$ Figura 3, encontram-se apresentadas as correlações entre valores diários de evapotranspiração de referência, estimados pelos métodos estudados e medidos no lisímetro de lençol freático constante.

Observa-se, na Figura 3, que os métodos FAOPenman Modificado, FAO-Radiação, HargreavesSamani, FAO-Penman-Monteith e o Irrigâmetro superestimaram a evapotranspiração de referência. $\mathrm{O}$ método do Tanque Classe $\mathrm{A}$ subestimou a $\mathrm{ET}_{0}$ para valores menores do que $2,5 \mathrm{~mm} \mathrm{~d}^{-1}$, ocorrendo comportamento contrário para valores maiores.
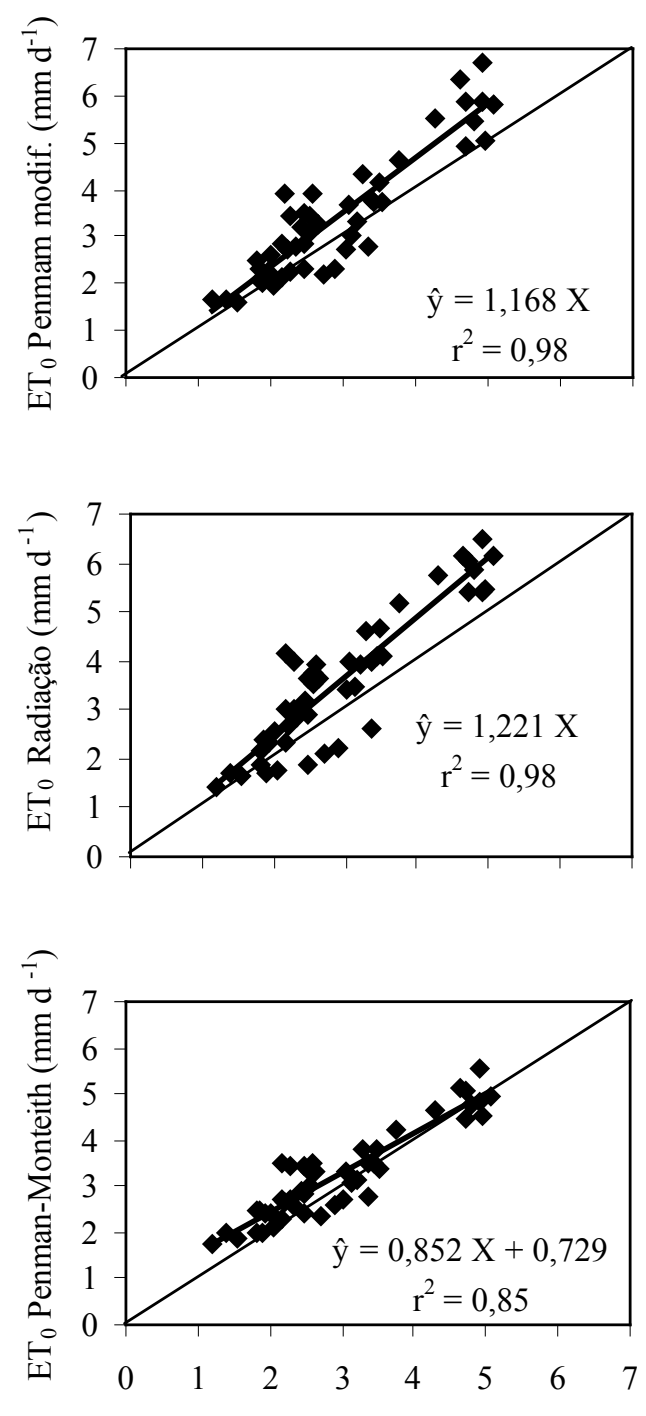

$\mathrm{ET}_{0}$ Lisímetro modificado $\left(\mathrm{mm} \mathrm{d}^{-1}\right)$
Apesar de esse método ter apresentado menor Erro Padrão da Estimativa, a dispersão dos dados não acompanhou a linha de valores 1:1.

Na Figura 3, a linha de tendência obtida para o Irrigâmetro, para o método da radiação e para o método FAO-Penman-Monteith apresentou a mesma tendência, acompanhando praticamente a linha de valores $1: 1$, para todos os valores de evapotranspiração de referência. Isso demonstra que os valores obtidos por esses métodos estão bem correlacionados com os do método do lisímetro de lençol freático constante.
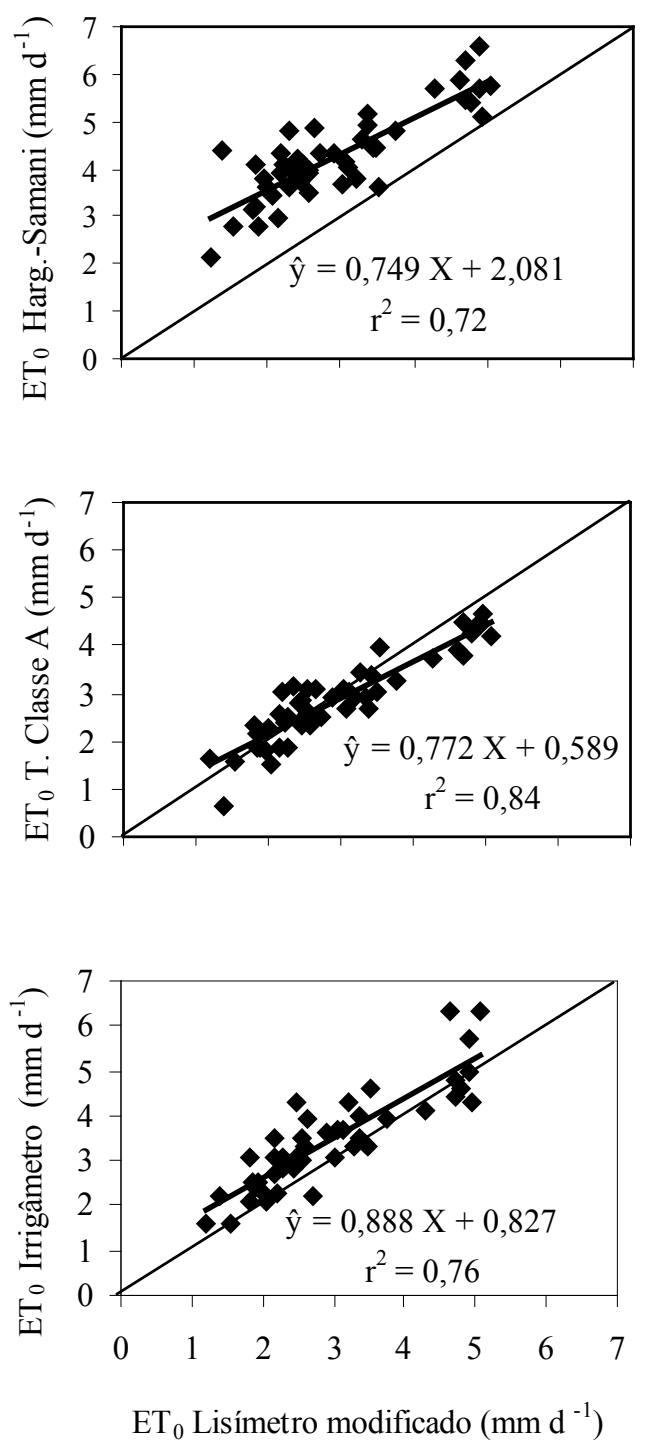

Figura 3. Relação entre os valores deET0 determinada pelos métodos FAO24-Penman Modificado, HargreavesSamani, FAO24-Radiação, Tanque Classe A, FAO56-Penman-Monteith e pelo Irrigâmetro, com os valores de ET0 obtida pelo método do lisímetro de lençol freático constante para intervalos de um dia. 
As comparações dos métodos nos períodos de três, cinco e sete dias seguiram a mesma metodologia estatística aplicada na escala diária, sendo apresentadas no Quadro 2.

No Quadro 2, observa-se que o agrupamento da $\mathrm{ET}_{0}$ em intervalos de três, cinco e sete dias, respectivamente, resultou em aumento dos Coeficientes de Determinação e de Ajuste, com valores mais próximos da unidade, e em redução do Erro Padrão da Estimativa, com valores mais próximos de zero, para a maioria dos métodos estudados, comparativamente ao período diário.

Para os períodos de três, cinco e sete dias, utilizando-se o Irrigâmetro foram obtidos valores dos EEP iguais a $0,65,0,55$ e $0,55 \mathrm{~mm} \mathrm{~d}^{-1} \mathrm{e}$ coeficientes de ajustamento iguais a 0,87, 0,89 e 0,90 , respectivamente, indicando desempenho similar aos obtido quando se utiliza o método FAO-Penman Modificado para estimativa da $\mathrm{ET}_{0}$.

Nas Figuras 4, 5 e 6, encontram-se apresentados as correlações entre valores diários de evapotranspiração de referência estimados pelos métodos estudados e pelos medidos no lisímetro de lençol freático constante, para intervalos de três, cinco e sete dias, respectivamente.

Quadro 2. Parâmetros da Regressão (a, b), Coeficiente de Determinação $\left(\mathrm{r}^{2}\right)$, Erro Padrão da Estimativa (EEP) e o Índice de Concordância (d), obtidos entre os valores de ET $_{0}$ estimada no Irrigâmetro e pelos demais métodos estudados, com os valores medidos no lisímetro de lençol freático constante, para períodos de três, cinco e sete dias.

\begin{tabular}{lcccccc}
\hline Método & $\mathrm{a}$ & $\mathrm{b}$ & $\mathrm{r}^{2}$ & $\mathrm{EPE}$ & $\mathrm{d}$ & $\mathrm{ET}_{0}\left(\mathrm{mmd}^{1}\right)$ \\
\hline & Três dias & & & & & \\
& & & & & & \\
\hline Lisímetro de lençol freático constante & - & - & - & - & - & 2,99 \\
FAO-Penman-Monteith & 0,753 & 0,828 & 0,90 & 0,37 & 0,95 & 3,23 \\
FAO-Penman modificado & 0,000 & 1,143 & 0,99 & 0,58 & 0,90 & 3,43 \\
Hargreaves-Samani & 1,901 & 0,807 & 0,83 & 1,41 & 0,64 & 4,32 \\
FAO-Radiação & 0,000 & 1,191 & 0,99 & 0,74 & 0,87 & 3,57 \\
Tanque Classe A & 0,811 & 0,696 & 0,95 & 0,32 & 0,95 & 2,89 \\
Irrigâmetro & 1,014 & 0,831 & 0,81 & 0,65 & 0,87 & 3,50 \\
\hline
\end{tabular}

Cinco dias

\begin{tabular}{lcccccc} 
Lisímetro de lençol freático constante & - & - & - & - & - & 3,07 \\
FAO-Penman-Monteith & 0,000 & 1,047 & 0,99 & 0,37 & 0,94 & 3,26 \\
FAO-Penman modificado & 0,000 & 1,168 & 0,99 & 0,66 & 0,88 & 3,57 \\
Hargreaves-Samani & 1,586 & 0,905 & 0,88 & 1,39 & 0,65 & 4,36 \\
FAO-Radiação & 0,000 & 1,162 & 0,99 & 0,72 & 0,84 & 3,59 \\
Tanque Classe A & 0,834 & 0,682 & 0,86 & 0,37 & 0,93 & 2,93 \\
Irrigâmetro & 0,000 & 1,122 & 0,99 & 0,55 & 0,89 & 3,49 \\
\hline
\end{tabular}

Sete dias

\begin{tabular}{lcccccc}
\hline Lisímetro de lençol freático constante & - & - & - & - & - & 2,98 \\
FAO-Penman-Monteith & 0,655 & 0,870 & 0,99 & 0,32 & 0,96 & 3,25 \\
FAO-Penman modificado & 0,000 & 1,158 & 0,99 & 0,54 & 0,92 & 3,46 \\
Hargreaves-Samani & 1,701 & 0,886 & 0,89 & 1,50 & 0,63 & 4,34 \\
FAO-Radiação & 0,000 & 1,204 & 0,99 & 0,71 & 0,87 & 3,60 \\
Tanque Classe A & 0,693 & 0,833 & 0,96 & 0,29 & 0,96 & 2,90 \\
Irrigâmetro & 0,764 & 0,909 & 0,98 & 0,55 & 0,90 & 3,48 \\
\hline
\end{tabular}



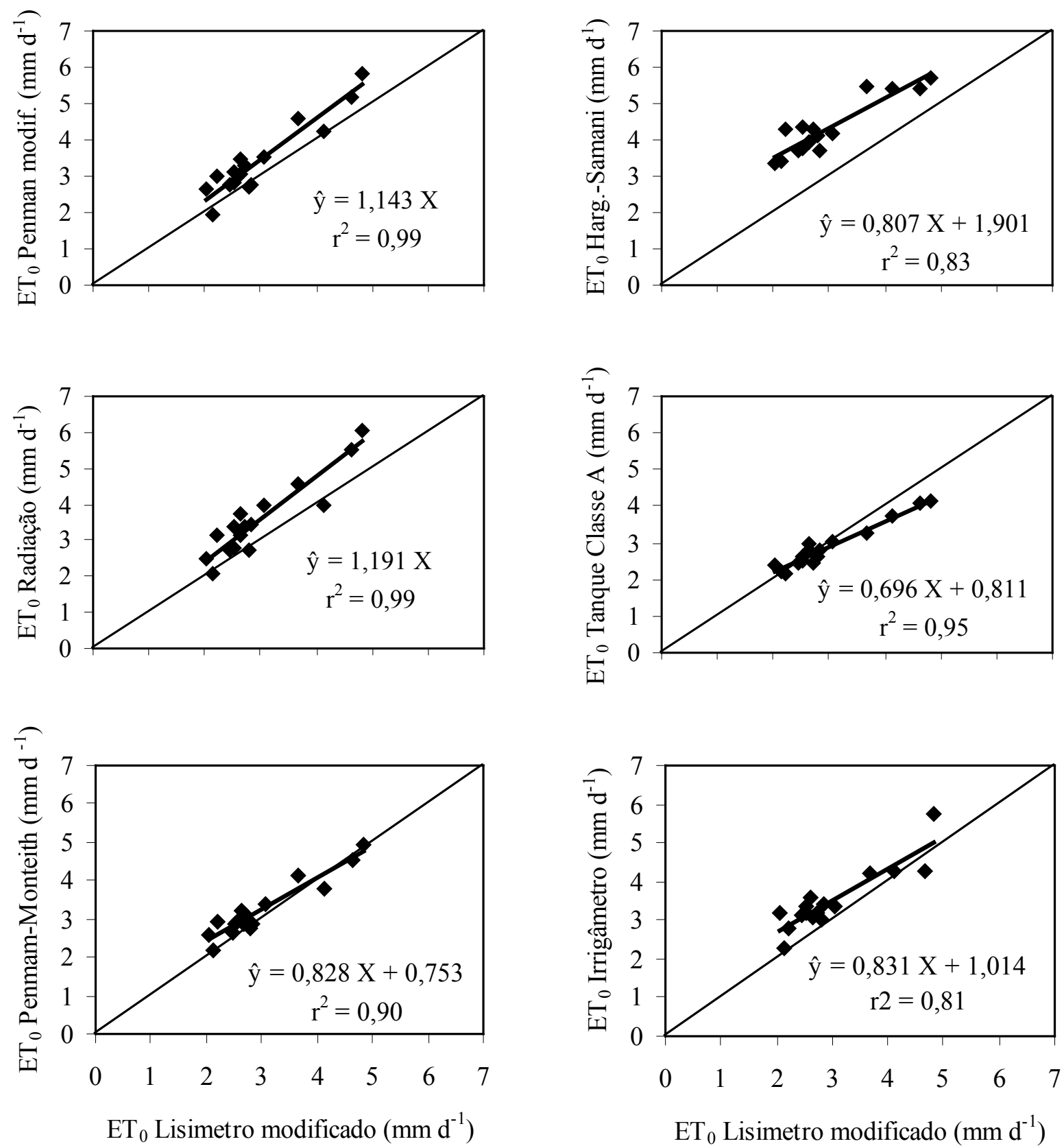

Figura 4. Relação entre os valores de ET0 estimados pelos métodos FAO24-Penman Modificado, Hargreaves-Samani, FAO24-Radiação, Tanque Classe A, FAO56-Penman-Monteith e pelo Irrigâmetro, com os valores de ET0 medidos no lisímetro de lençol freático constante para intervalos de três dias. 

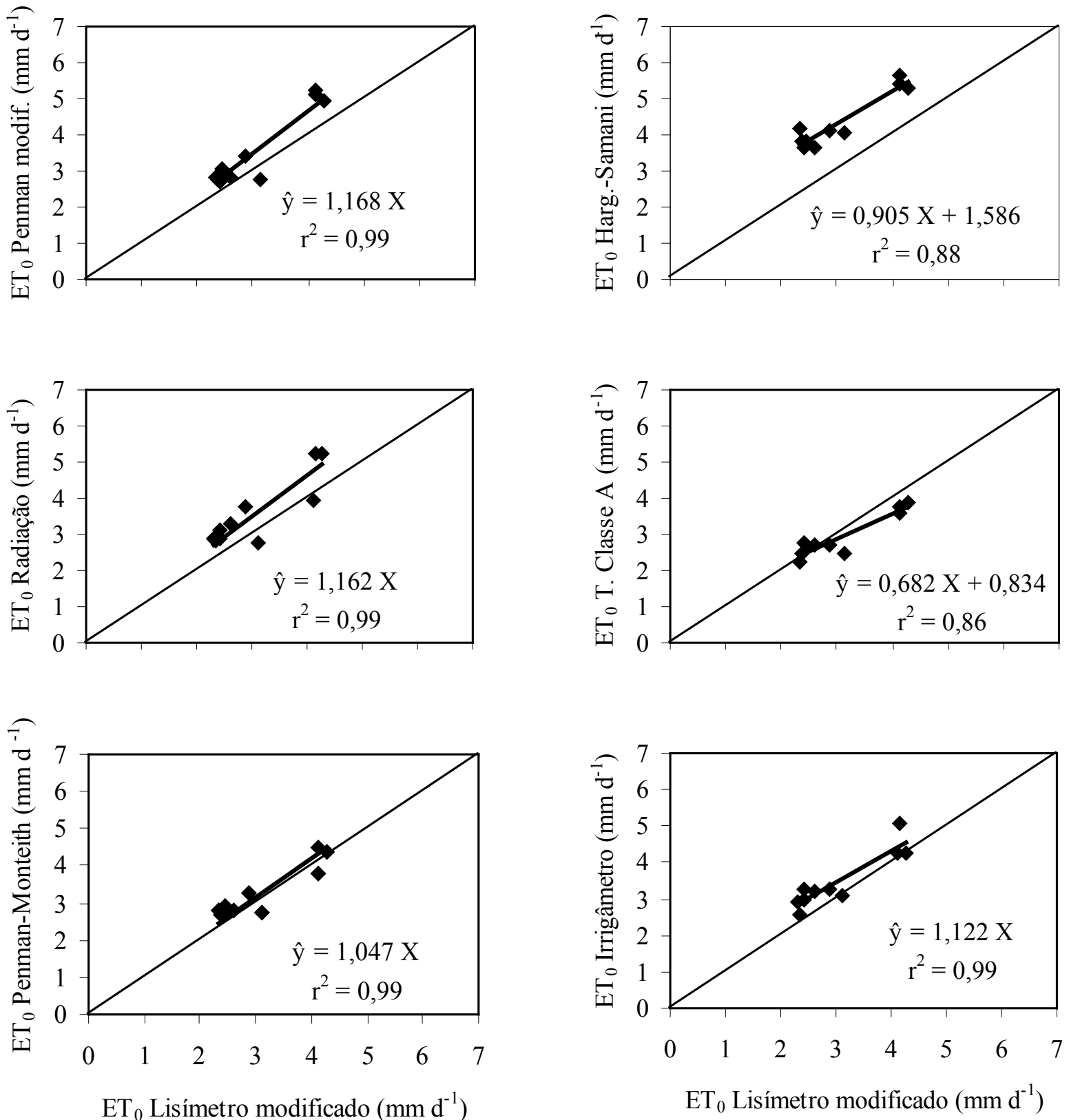

Figura 5. Relação entre os valores de ET0 estimados pelos métodos FAO24-Penman Modificado, Hargreaves-Samani, FAO24-Radiação, Tanque Classe A, FAO56-Penman-Monteith e pelo Irrigâmetro, com os valores de ET0 medidos no lisímetro de lençol freático constante para intervalos de cinco dias. 

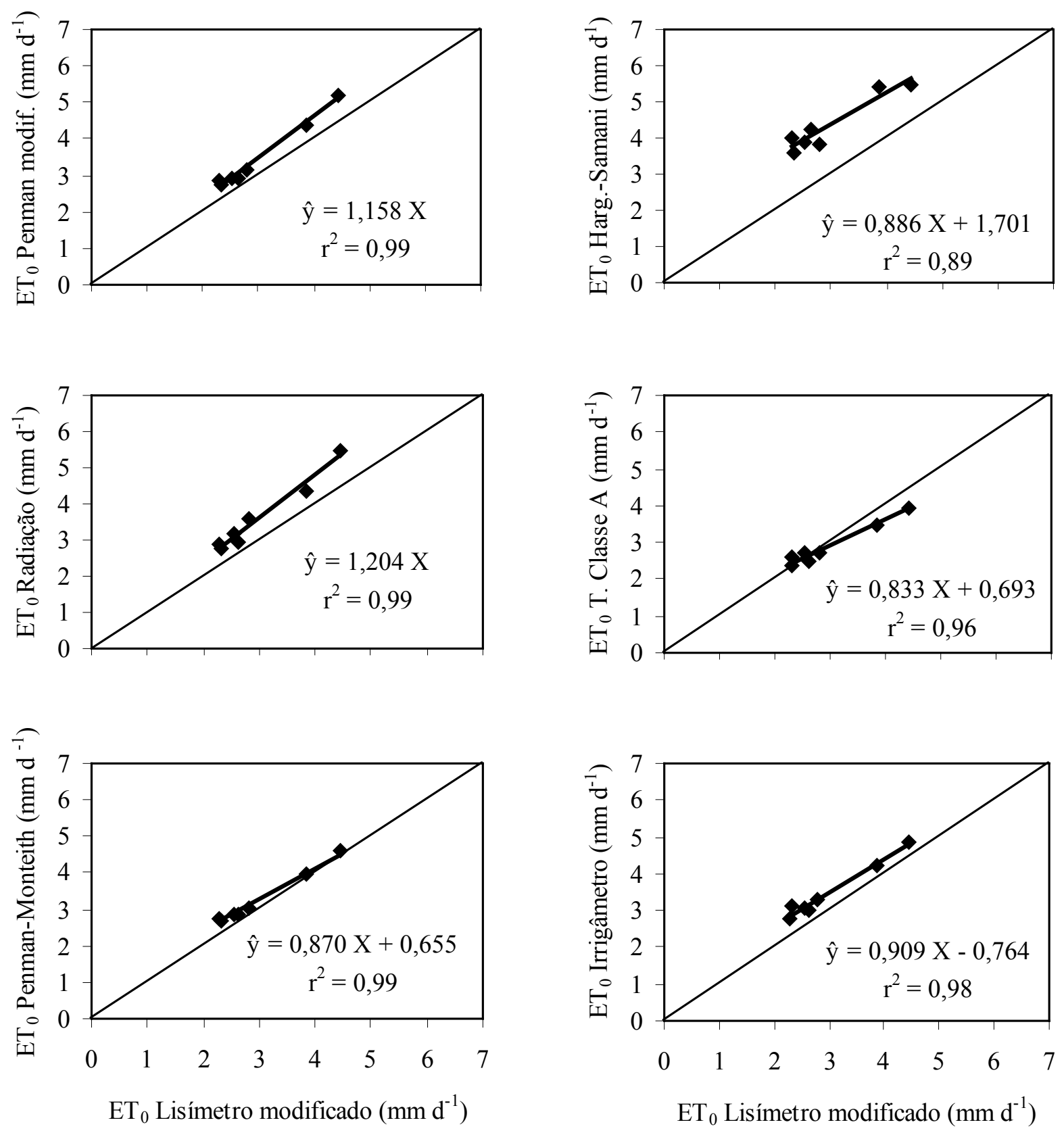

Figura 6. Relação entre os valores de ET0 estimados pelos métodos FAO24-Penman Modificado, Hargreaves-Samani, FAO24-Radiação, Tanque Classe A, FAO56-Penman-Monteith e pelo Irrigâmetro, com os valores de ET0 medidos no lisímetro de lençol freático constante para intervalos de sete dias. 
A análise das Figuras 4, 5 e 6 mostra que o agrupamento dos valores de $\mathrm{ET}_{0}$ em períodos maiores tende a melhorar a estimativa, tendo sido mantido o mesmo comportamento obtido quando da utilização dos outros métodos estudados. O método de Hargreaves-Samani foi, dentre os métodos estudados, o que mais proporcionou superestimativas da $\mathrm{ET}_{0}$, independentemente do período de comparação. Jensen et al. (1990) encontraram boas estimativas de $\mathrm{ET}_{0}$ quando utilizaram o método de Hargreaves-Samani, para intervalos de tempo maiores do que dez dias.

O Tanque Classe A possibilitou que se obtivessem melhorias na estimativa da $\mathrm{ET}_{0}$ para períodos de sete dias, apresentando maior precisão comparativamente aos obtidos nos demais períodos de tempo analisados (DOORENBOS \& PRUITT, 1977; JENSEN et al., 1990).

Nos intervalos de tempo analisados, o Irrigâmetro superestimou os valores médios de evapotranspiração de referência obtidos utilizandose o método padrão (lisímetro). Entretanto, os seus resultados em relação à linha 1:1 foram praticamente iguais aos obtidos quando se utilizou o método FAO-Penman Modificado, recomendado pela FAO (Boletim 24). Esses resultados demonstram que o aparelho pode ser recomendado para estimar a $\mathrm{ET}_{0}$.

\section{CONCLUSÕES}

- O Irrigâmetro proporcionou desempenho adequado e semelhante na estimatica da $\mathrm{ET}_{\mathrm{O}}$, nos períodos de um, três, cinco e sete dias, ao método FAO - Penman modificado;

- O Irrigâmetro pode ser indicado para utilização no manejo da água na agricultura irrigada, por apresentar resultados de estimativa de $\mathrm{ET}_{\mathrm{O}}$ semelhantes aos métodos recomendados nos Boletins FAO 24 e 56;

- O método do Tanque Classe A proporcionou subestimativa de $\mathrm{ET}_{0}$, obtida pelo método do lisímetro de lençol freático constante, mesmo tendo apresentado melhor desempenho em relação aos métodos estudados de estimativa empírica; e

- Todos os métodos estudados proporcionaram superestimativa da evapotranspiração de referência, obtida no lisímetro de lençol freático constante, exceto do Tanque Classe A. Os métodos de Hargreaves-Samani e FAO-Radiação proporcionaram as maiores superestimativas da $\mathrm{ET}_{0}$.

\section{REFERÊNCIAS BIBLIOGRÁFICAS}

ALLEN, R.G.A Penman for all seasons. Journal of Irrigation and Drainage Engineering, New York, v.112, n.4, p.348-386, 1986.

ALLEN, R.G. REF-ET: Reference evapotranspiration calculator, Version 2.1. Idaho: Idaho University, 2000. 82p.

ALLEN, R.G.; PRUITT, W.O. Reference evapotranspiration factors. Journal Irrigation and Drainage Engineering, New York, v.117, n.5, p.758772, 1991.

BERLATO, M.A.; MOLION, L.C.B. Evaporação e evapotranspiração. Porto Alegre: IPAGRO: Secretaria de Agricultura, RS. 1981. 95p. (Boletim Técnico, 7).

BURMAN, R.D.; NIXON, P.R.; WRIGHT, T.L.; PRUITT, W.O. Water requeriments. In: JENSEN, M. E. Design operation of farm irrigation system. Transactions of ASAE, St. Joseph: ASAE, 1983. p.189-232.

CAMARGO, A.P.; SENTELHAS, P.C. Avaliação do desempenho de diferentes métodos de estimativa da evapotranspiração potencial no Estado de São Paulo.

Revista Brasileira de Agrometeorologia, Santa Maria, v.5, n.1, p.89-97, 1997.

DOORENBOS, J.; PRUITT, J.O. Crop water requirement. Rome: FAO, 1977. 144p. (FAO Irrigation and Drainage Paper 24).

HARGREAVES, G.H.; SAMANI, Z.A. Reference crop evapotranspiration from temperature Applied Engineering in Agriculture, New York, v.1, n.2, p.96-99, 1985.

HOWELL, T.A.; SCHNEIDER, A.D.; JENSEN, M.E. History of lysimeter design 
and use for evapotranspiração. In: Lysimiter for evapotranspiration and environment measurements. New York: ASCE, 1991. p. $1-19$.

JENSEN, M.E.; BURMAN, R.D.; ALLEN, R.G. Evapotranspiration and irrigation water requirements. New York: ASCE, 1990. 332p.

LEY, T.W.; HILL, R.W.; JENSEN, D.T. Errors in Penman-Wright alfalfa reference evapotranspiration estimates: I. Model sensitivity analyses. Transactions of ASAE, St. Joseph, v.37, n.6, p.1853-1861, 1994a.

LEY, T.W.; HILL, R.W.; JENSEN, D.T. Errors in Penman-Wright alfalfa reference evapotranspiration estimates: II. Effects of weather sensor measurement variability. Transactions of ASAE, St. Joseph, v.37, n.6, p.1863-1870, 1994 b.

LUNARDI, M.A.; LUNARDI, D.M.C.; CAVATI, N. Comparação entre medidas evapotranspirométricas e metodológicas da FAO, na determinação da evapotranspiração de referência. IRRIGA, Botucatu, v.4, n.1, p.52-66, 1999.

MATERAN, F.J.V. Tecnologia do irrigâmetro aplicada em minilisímetros e lisímetros com lençol freático constante para determinação da evapotranspiração de referência. 2006. 96f. Tese (Doutorado em Engenharia Agrícola) - Universidade Federal de Viçosa, Viçosa, 2006.

OLIVEIRA, R.A. de; TAGLIAFERRE, C. Irrigâmetro: nova tecnologia para manejo da água de irrigação. In: BARBOSA, T.C.; TANIGUCHI, G.C.; PENTEADO, D.C.S.; SILVA, D.J.H. da. Ambiente protegido: olericultura, citricultura e floricultura. Viçosa: UFV, 2006, p. 39-64.
OLIVEIRA,R.A.de; TAGLIAFERRE, C.; SEDIYAMA, G.C.; MATERAN, F.J.V.; CECON, P.R. Desempenho do Irrigâmetro na estimativa da Evapotranspiração de referência. Revista Brasileira de Engenharia Agrícola e Ambiental. Campina Grande, v.12, n.2, p.166-173, 2008.

PEREIRA, F.A de C. Desempenho do modelo de Penmam-Monteith e de dois evaporímetros na estimativa da evapotranspiração de referência (ET) em relação a um lisímetro de pesagem. 1998. 87f. Tese (Doutorado em Irrigação e Drenagem) - Escola Superior de Agricultura 'Luiz de Queiroz", Universidade de São Paulo, Piracicaba, 1998.

SENTELHAS, P.C. Estimativa diária da evapotranspiração de referência com dados de estação meteorológica convencional e automática. 1998. 97f. Tese (Doutorado em Irrigação e Drenagem) - Escola Superior de Agricultura “Luiz de Queiroz", Universidade de São Paulo, Piracicaba, 1998.

TAGLIAFERRE, C. Desempenho do Irrigâmetro e de dois minievaporímetros para estimativa da evapotranspiração de referência. 2006. 99f. Tese (Doutorado em Engenharia Agrícola) - Universidade Federal de Viçosa, Viçosa, 2006.

TAGLIAFERRE， C.; OLIVEIRA， R.A. de; SEDIYAMA, G.C.; CECON, P.R.; DENICULI, W.; MARTINEZ, M.A.; MATERAN, F.J.V. Estimativa da evapotranspiração de referência usando minievaporímetro operando com irrigâmetro modificado. Engenharia na Agricultura, Viçosa, v.14, n.3, p.212-223, 2006.

WILLMOTT, C.J.; CKLESON, S.G.; DAVIS, R.E. Statistics for evaluation and comparisons of models. Journal of Geophysical Research, Ottawa, v.90, n.C5. p.8995-9005, 1985. 